\title{
"Eu não Sou Homem Mais!": Masculinidades e Experiências de Adoecimento por Câncer da Próstata
}

\section{"I am not a man anymore!": Masculinities and Illness Experiences of Prostate Cancer}

\author{
Alberto Mesaque Martins (orcid.org/0000-0002-6032-3122) 1 \\ Adriano Roberto Afonso do Nascimento (orcid.org/0000-0002-7752-01 14)2
}

\begin{abstract}
Resumo
Este estudo buscou compreender a maneira como os homens experienciam o processo de adoecimento por câncer da próstata e analisar suas experiências relacionadas ao tratamento oncológico. Foram realizadas entrevistas narrativas episódicas com oito homens, com idade entre 50 e 70 anos, diagnosticados com câncer da próstata e que declararam ter concluído o tratamento, analisadas por meio da Análise Fenomenológica Interpretativa. Para os entrevistados, o câncer é uma doença grave, complexa, agressiva e fortemente associada à morte e ao sofrimento. As limitações físicas e a nova rotina impostas pelo adoecimento e tratamento mostram-se bastante diferentes dos modos de vida dos homens anteriores à enfermidade e produziram sentimentos de medo e ansiedade quanto à possibilidade da morte e do sofrimento. O adoecimento e o tratamento exigiram que os indivíduos reelaborassem suas concepções acerca de seus corpos e abriu espaço para construção de novas formas de se pensar e viver a própria masculinidade.
\end{abstract}

Palavras-chave: Masculinidades. Câncer da Próstata. Psicologia Social.

\begin{abstract}
This study aimed to understand the way men experience the illness process of prostate cancer and to analyze their experiences related to cancer treatment. Episodic narrative interviews were conducted with 08 men, aged between 50 and 70 years, diagnosed with prostate cancer and who reported having completed treatment, analyzed through the Interpretative Phenomenological Analysis. According to the interviewees, the cancer is a serious illness, complex, aggressive and strongly associated with death and suffering. The physical limitations and the new routine imposed by the illness and treatment are very different from the livelihoods of men before the illness, and produced feelings of fear, anxiety about the possibility of death and suffering. The illness and the treatment required that men develop their ideas about their bodies and opened space for construction of new ways of thinking and living masculinity.
\end{abstract}

Keywords: Masculinities. Prostate Cancer. Social Psychology.

\footnotetext{
${ }^{1}$ Universidade Federal de Mato Grosso do Sul, Campo Grande, Brasil. E-mail: albertomesaque@yahoo.com.br

${ }^{2}$ Universidade Federal de Minas Gerais, Belo Horizonte, Brasil. E-mail: nascimentopsi72@gmail.com
} 


\section{Introdução}

O câncer, ainda hoje, é um importante problema de Saúde Coletiva que, apesar dos esforços governamentais para controle e prevenção, apresenta crescentes taxas de incidência e prevalência, especialmente, nos países em desenvolvimento (Inca, 2016). Estima-se que, até o ano de 2025, serão registrados cerca de 20 milhões de novos casos da doença, com uma maior morbimortalidade entre a população masculina (Inca, 2016).

No Brasil, segundo o Instituto Nacional de Câncer José de Alencar (Inca), órgão do Ministério da Saúde voltado para estudos e intervenções em Oncologia, estima-se que, em cada ano do triênio 2020-2022, serão constatados 625 mil novos casos de cânceres, sendo as neoplasias da próstata a mais recorrente entre os homens brasileiros (Inca, 2016). Atualmente, a mortalidade por neoplasias configura-se como a terceira principal causa de morte entre os homens brasileiros, revelando-se como um tema importante, frequentemente inserido nas agendas de discussões sobre a saúde masculina (Schwarz et al., 2012; Belinelo et al., 2014; Martins \& Modena, 2016a).

Estudos apontam para o distanciamento dos homens dos serviços de saúde (Almeida \& Santos, 2011; Amorin et al., 2011; Nascimento, Trindade \& Gianordoli-Nascimento, 2011; Schwarz et al., 2012; Moura, Gomes \& Pereira, 2017), bem como para a dificuldade que essas instituições ainda encontram para incorporar esses sujeitos na pauta de ações assistenciais (Martins, Gazzinelli, Almeida \& Modena, 2013; Martins \& Modena, 2016b; Moreira, Gomes \&
Ribeiro, 2016), refletindo na busca de atendimentos e diagnóstico tardios, frequentemente, em casos de doenças já manifestas e em estágios avançados de adoecimento (Mesquita, Moreira \& Maliski, 2011; Martins, Gazzinelli, Almeida \& Modena, 2012; Martins \& Modena, 2016a). Diversos estudos apontam que o mesmo ocorre depois do diagnóstico do câncer, já que os homens também apresentam dificuldades de aderir aos tratamentos propostos e de se adaptar à nova rotina de cuidados, revelando marcas do processo de construção social das masculinidades (Gomes, Nascimento, Rebello \& Araújo, 2008; Gannon, Guerro-Blanco, Patel \& Abel, 2010; Mesquita et al., 2011; Krumwiede \& Krumwiede, 2012; Martins et al., 2012; Burille, Schwartz \& Zillmer, 2013; Modena, Martins, Gazzinelli, Almeida \& Schall; 2014, King et al., 2015; Chambers, Chung, Wittert \& Hyde, 2017). Esse distanciamento torna-se ainda maior quando consideradas as enfermidades que acometem o aparelho genital e urológico, como o câncer da próstata (Amorin et al., 2011; Belinelo et al., 2014; Campbell, Keefe \& McKee, 2014; Novak \& Sabino, 2015). Diferentes estudos apontam para a influência dos modos de conceber e exercitar a masculinidade no distanciamento dos homens das ações de prevenção e diagnóstico precoce do câncer da próstata (Gomes et al., 2008; Kelly, 2009; Belinelo et al., 2014; King et al., 2015). Desse modo, ainda hoje, é recorrente que homens pertencentes a diferentes grupos sociais e com diferentes níveis de escolaridade resistam à realização do exame de toque retal, frequentemente percebido como uma violação 
sexual e um comportamento que minimiza sua virilidade e indicaria uma suposta homossexualidade (Amorin et al., 2011; Paiva, Motta \& Griep, 2011; Martins \& Modena, 2016a).

Esse cenário parece refletir os efeitos do modelo de masculinidade hegemônica que, segundo Connel e Messerschmidt (2013), referese a um modo específico de ser-homem difundido cotidianamente por meio de diferentes instituições sociais, por exemplo, a família, a escola, o trabalho, entre outras, e que exige que os homens, desde tenra idade, persigam e exerçam comportamentos e atitudes que atestem, perante outros homens, a sua virilidade e hombridade, comprometendo, muitas vezes, seu bem-estar e sua qualidade de vida (Nascimento et al., 2011; Connell \& Messerschmidt, 2013; Martins \& Modena, 2016; Moreira et al., 2016; Moura et al., 2017). Sendo assim, desde a infância, os meninos são incentivados a atestarem sua hombridade por meio de práticas que incluem violência física, envolvimento em situações de risco e outras ações que confirmem o seu sentimento de invulnerabilidade (Nascimento et al., 2011; Connell \& Messerschmidt, 2013; Martins \& Modena, 2016).

Assim, os sentidos atribuídos ao serhomem, permeados pelas imposições do modelo hegemônico de masculinidade, também vêm sendo apontados como fatores que dificultam e, em alguns casos, impossibilitam o desempenho de práticas adequadas de autocuidado e a utilização dos serviços de saúde por esse público específico (Kelly, 2009; Nascimento et al., 2011; Martins \& Modena,
2016후 Moura et al., 2017). Estudos realizados em diferentes contextos encontram no modelo de masculinidade hegemônica uma barreira que dificulta e, em alguns casos, inviabiliza a mobilização dos homens para as ações em saúde, especialmente aquelas voltadas para a promoção da saúde e prevenção de enfermidades (Schwarz et al., 2012; Moreira et al., 2016; Moura et al., 2017). Por outro lado, as crenças sobre e prescrições sociais sobre os "homens de verdade" não se restringem aos usuários dos serviços de saúde. Diferentes estudos vêm constatando que os profissionais de saúde, de ambos os sexos, também são influenciados pelo modelo de masculinidade hegemônica e, portanto, carregam para as instituições de saúde sentidos e atitudes relacionados às masculinidades, que inviabilizam os homens que utilizam esses dispositivos e dificultam o reconhecimento desse grupo como sujeitos do cuidado (Gomes et al., 2008; Martins et al., 2013; Martins \& Modena, 2016b; Moreira et al., 2016).

Reconhecendo como válido esse conjunto de considerações, somos levados a admitir a necessidade de que o processo de saúde/adoecimento/cuidado seja compreendido em uma perspectiva que também integre a dimensão cultural (Jodelet, 2006). Nessa perspectiva, Jodelet (2006) reafirma a indissociabilidade do processo de adoecimento da cultura e da história de vida do sujeito e dos grupos sociais aos quais pertencem. Ao reconhecer essa inseparabilidade, abre-se espaço para consideração da experiência subjetiva dos sujeitos que adoecem, bem como oportunidades para que os seus modos de pensar, sentir e agir, devido ao adoecimento, sejam considerados 
(Jodelet, 2006).

Embora a experiência de adoecimento se refira a um evento singular, individual e, portanto, subjetivo, ao mesmo tempo, ela também se configura como um fenômeno socialmente elaborado e compartilhado Jodelet, 2006). Desse modo, a experiência remete ao social e é a partir das pré-construções culturais e de conhecimentos previamente construídos e compartilhados que ela ganha sentido para os sujeitos que a experienciam, podendo ser também comunicada e socialmente elaborada por seus grupos de pertença (Jodelet, 2006).

Nesse ponto, parece ser conveniente indicar que a noção de experiência abarca duas dimensões: a do conhecimento e a do experimentado (Jodelet, 2005). Na dimensão do experimentado situam-se as experiências diretamente relacionadas ao vivido, permeadas pelos afetos e pelas emoções que possibilitam que o sujeito tome consciência de sua subjetividade e identidade. Essa dimensão remete à forma como o fenômeno da experiência se apresenta para aquele que a experiencia, considerando os aspectos afetivos e emocionais relacionados ao evento. Conforme destaca Jodelet (2006, p. 29), a experiência vivida se refere ao: "modo através do qual as pessoas sentem uma situação em seu foro íntimo, e o modo como elas elaboram através de um trabalho psíquico e cognitivo, as ressonâncias positivas e negativas dessa situação e das relações e ações que eles desenvolvem naquela situação".

Já a dimensão do conhecimento diz respeito aos aspectos cognitivos da experiência, quando o sujeito que experiencia, ao mesmo tempo, busca produzir sentidos que o ajudem a compreender os acontecimentos, situações, objetos e pessoas que compõem o seu mundo de vida (Jodelet, 2005). Ainda, segundo esse autor (2005, p. 33), a produção de sentido para as experiências, tanto no que tange à dimensão experimentada como à do conhecimento, não se dá alheia ao contexto social no qual os sujeitos se encontram inseridos. Desse modo, "a experiência social é marcada pelos aspectos sociais de sua enunciação e de sua comunicação". Tendo em vista o aumento contínuo de novos casos de câncer da próstata entre homens brasileiros, e considerando seus impactos na corporeidade e na identidade masculina, percebe-se a necessidade de ampliar a compreensão acerca do processo de adoecimento e tratamento oncológico, numa perspectiva que considere as dimensões do conhecimento e do experimentado. Nessa perspectiva, e ancorado na compreensão da experiência de adoecimento como um fenômeno, ao mesmo tempo singular e social (Jodelet, 2006), este estudo tem como objetivo compreender a maneira como os homens experienciam o processo de adoecimento por câncer da próstata e analisar as suas experiências relacionadas ao tratamento oncológico.

\section{Método}

Trata-se de uma pesquisa exploratória, de caráter qualitativo. Foram realizadas entrevistas narrativas episódicas (Flick, 2009) com oito homens, selecionados a partir dos seguintes critérios de intencionalidade: ter entre 50 e 70 anos de idade, haver sido diagnosticado 
com câncer da próstata, declarar ter concluído o tratamento oncológico há pelo menos seis meses e aceitar o convite de participação.

Inicialmente, os pesquisadores buscaram acessar os participantes por meio da Técnica de Bola de Neve. Desse modo, o pesquisador indicaria o primeiro participante a partir de sua rede pessoal de contatos, levando em consideração os critérios de intencionalidade expostos anteriormente. Ao fim de cada entrevista, cada sujeito indicaria um novo participante que também atendesse aos critérios de seleção, entretanto, essa estratégia não se mostrou eficaz. Assim, os pesquisadores fizeram contato com instituições filantrópicas e beneficentes, que atuam como casas de apoio a pacientes oncológicos, localizadas na cidade de Belo Horizonte (MG). Depois da identificação dessas instituições, foi feito contato com o Serviço de Psicologia de cada uma delas, propondo a parceria para indicação de participantes que atendessem aos critérios de seleção da pesquisa. Essa estratégia possibilitou identificar duas casas de apoio, as quais indicaram seis participantes. Outros dois sujeitos foram selecionados por meio da rede de contatos pessoais de um dos pesquisadores.

As entrevistas foram realizadas em locais indicados pelos próprios participantes e orientadas por um roteiro semiestruturado que procurou abordar o processo de adoecimento por câncer e tratamento oncológico e duraram em média 90 minutos. Em geral, os participantes têm idade entre 58 e 68 anos, sendo todos casados e com filhos. A idade dos participantes reflete o perfil dos homens diagnosticados com câncer da próstata, mais incidente depois dos 50 anos de idade. No período que antecede ao diagnóstico de câncer, a maior parte dos entrevistados trabalhava em atividades relacionadas à construção civil, mineração e atendimento em bares e restaurantes. No momento da pesquisa, apenas um dos entrevistados seguia trabalhando, enquanto os demais estavam desempregados, aposentados ou afastados do trabalho.

Para análise dos dados, foi utilizada a Abordagem Fenomenológica Interpretativa (AFI), que concebe os sujeitos como seres autointerpretantes que, a todo o instante, encontram-se mobilizados a interpretar os fenômenos, eventos, objetos e pessoas que integram o seu cotidiano, buscando dar sentido às suas experiências (Smith \& Eatough, 2010). A AFI vem sendo reconhecida na literatura científica como um importante método de análise de dados, capaz de ampliar a compreensão de experiências e narrativas, como as que compuseram o presente estudo (Giorgi, 2008). Mais especificamente, foi utilizada a proposta de Trindade, Menandro e GianordoliNascimento (2007), que apresentam uma possibilidade de aplicação da AFI em estudos de Psicologia Social.

Segundo as instruções de Trindade, Menandro e Gianordoli-Nascimento (2007), no primeiro momento, realizou-se a transcrição literal das entrevistas, pelos próprios pesquisadores, sem suprimir nenhuma fala. Em seguida, foi realizada a leitura exaustiva das transcrições integrais, mantendo uma atitude de redução fenomenológica, buscando construir unidades de significado. No terceiro momento, os trechos das entrevistas foram reorganizados a 
partir dos temas e das unidades identificadas, respeitando a transcrição literal. Em seguida, os relatos relevantes para o tema do estudo foram convertidos em linguagem parcialmente padronizada e, por fim, na quinta e última etapa, os temas e as unidades de significado foram transformados em uma estrutura que considerou os significados e as experiências dos participantes relativos ao fenômeno de estudo, possibilitando, assim, a interpretação dos dados e a construção dos resultados (Trindade et al., 2007).

Todos os participantes tiveram conhecimento dos objetivos da pesquisa e assinaram o Termo de Consentimento Livre e Esclarecido. O projeto de pesquisa foi submetido ao Comitê de Ética em Pesquisa da Universidade Federal de Minas Gerais e recebeu aprovação por meio do Parecer n. 451.027 (CAAE n. 19533413.6.0000.5149), em cumprimento da Resolução n. 466/2012 do Conselho Nacional de Saúde.

\section{Resultados}

Buscando adequar a apresentação dos resultados à estrutura deste manuscrito e visando fornecer uma melhor compreensão aos leitores, os resultados serão apresentados de uma maneira que já integra os relatos, os temas e as unidades de significado, enfatizando as experiências dos homens entrevistados em relação ao processo de adoecimento por câncer da próstata e ao tratamento oncológico. Para garantir o anonimato, os nomes dos participantes foram substituídos por pseudônimos.

\section{Concepções e Avaliações sobre o Câncer Sentidos Atribuídos ao Câncer}

Analisando as falas dos entrevistados, é possível perceber uma diversidade de significados relacionados ao câncer. Em geral, essa enfermidade é percebida pelos participantes como uma doença grave, complexa, agressiva, incurável e fortemente associada à morte. Nessa direção, Pierre afirma que o câncer "é um problema sério e que não tem cura"; já Patrício destaca que "o câncer é uma das doenças mais temidas" pelas pessoas.

A associação do câncer à morte aparece de forma evidente nas falas de quase todos os participantes. Nota-se, ainda, a recorrente tentativa dos entrevistados de organizar os cânceres em dois grupos: benignos e malignos. Para eles, os cânceres benignos se mostram menos agressivos e mais lentos. Já os malignos, por sua vez, se configuram como mais violentos e com maior probabilidade de matar. Assim, para Pierre, "o maligno é mais perigoso e mata a pessoa mais rápido". Segundo Pedro, "ele fode tudo".

Paulo diz que o câncer é uma "praga" que faz com que a pessoa fique "toda desanimada", levando-a a pensar "que vai morrer”. Conforme ele destaca, o câncer "maligno não é brincadeira! Ele mata mesmo". Por outro lado, para Paulo, o câncer "benigno ele vai devagarinho [...] Ele mata sim! Mata com o tempo!" Pierre é enfático ao considerar que "o câncer é a doença mais perigosa que tem", sendo o câncer maligno ainda "mais perigoso", pois "mata a pessoa mais rápido". Para ele, "o câncer é doença matadoura!". Já para Pablo o 
câncer "vem pra matar mesmo e não permite que a pessoa vai viver muito".

Muitos entrevistados reconhecem que outras pessoas, em seu círculo social, também compartilham da ideia de que o câncer é uma doença grave, agressiva e letal. Nesse sentido, Patrício destaca que, ainda hoje, "o câncer é uma das doenças mais temidas" pelas pessoas, já que "geralmente ela culmina em perda da vida, muitas das vezes fora do tempo". Por outro lado, apesar de, em alguns momentos, associarem o câncer à morte, alguns entrevistados também compartilham de avaliações menos negativas em relação à doença. Pedro, por exemplo, afirma que "a pessoa morre [de câncer] apenas se não tratar". De forma semelhante, Pacheco afirma que mudou a sua avaliação sobre essa doença depois de ser acometido por ela. Segundo ele, antes do diagnóstico, quando ouvia falar sobre o câncer, o imaginava como "um monstro, uma coisa feia, uma coisa ruim”, mas, agora, passou a considera-lo como uma "normalidade".

Para os participantes, o câncer é a uma doença silenciosa que, enquanto atua no corpo do indivíduo, não apresenta nenhum sinal de sua presença, revelando-se, assim, como uma doença "traiçoeira" (Pedro). Conforme destaca Patrício, o câncer da próstata é uma enfermidade que não apresenta "nenhum sinal", não apresenta "nenhum indicativo", nenhuma "dor" que permita ao homem identificá-la previamente. Segundo ele: "a gente não sente nada". Porém, para Pedro, o câncer "é uma doença traiçoeira" e silenciosa, pois, "às vezes, você tem câncer mas não sabe que tem e quando começa a doer é que está em fase terminal", levando-o a considerar que "o câncer é foda".
Os entrevistados

também compreendem o câncer como uma doença viva que se movimenta no corpo do sujeito acometido por ela. Mais uma vez, eles recorreram à ideia de divisão dos cânceres entre benignos e malignos, sendo esses últimos mais ágeis e produtores de maiores danos ao corpo, quando comparados aos benignos. Nessa direção, Paulo afirma que o câncer "maligno ele anda rápido" pelo corpo do sujeito: "você não pode deixar não, não dá tempo pra ele”, pois “ele leva o peão mesmo!" Para ele, o câncer benigno seria distinto, uma vez que "ele vai devagarinho, só devagarinho!”

Levando-se em consideração a ideia de que o câncer se movimenta pelo organismo, é possível observar que, para alguns dos entrevistados, esse movimento oferece um risco, uma vez que, para eles, ao se movimentar, o câncer também pode se "espalhar" pelo corpo do sujeito e acometer outros órgãos. Nesse sentido, foi recorrente que os participantes temessem a possibilidade de o câncer se espalhar pelo seu corpo e, como indica Pacheco, “aparecer em outro lugar”. Pacheco também se diz grato a Deus por não fazer seu "sangue circular tão rápido”, evitando assim que ele possa “distribuir essa doença para outros lugares" do seu corpo, fazendo com que ela fique "contida lá onde ela tá". Na mesma direção, Paulo afirma que o seu câncer deixou pra trás uma raiz, "o que causou ir pros ossos".

Associada a essa ideia de movimento dentro do organismo, alguns dos entrevistados concebem o câncer, em especial aquele percebido como maligno, como uma enfermidade que vai "comendo" o corpo, ao 
mesmo tempo em que se desloca por ele. Conforme destaca Paulo, "o negócio [câncer] é comilão mesmo, principalmente o maligno". Segundo Pierre, o câncer "fica comendo as pessoas aos poucos". Nesse sentido, depois do diagnóstico, os entrevistados também passaram a conviver com a possibilidade de que, depois do tratamento e da cura, o câncer regressasse em outro órgão ainda não acometido. Conforme destaca Pablo, o câncer "pode voltar de novo" e, de acordo com Pedro, nesses casos, ele "volta com mais intensidade" e, aí "não tem como", levando a pessoa a óbito.

Alguns entrevistados destacaram $\mathrm{O}$ caráter sobrenatural do câncer, revelando-o como uma doença originada de acordo com os desejos e interesses de Deus ou do demônio. Nessa perspectiva, Paulo afirma que, para ele, “o câncer parece que é uma doença que é do capeta", e Pierre ressalta que o câncer "é uma doença maligna, que não tem cura e que pode levar à morte a qualquer hora". Por outro lado, Pacheco afirma que o câncer pode ser determinado por Deus e, diante disso, nada pode fazer para modificar a situação na qual se encontra: "Se Deus determinou que isso veio pra mim, fazer o quê? Eu não vou contra Deus, não! [...] Deus é superior a tudo!” Ainda nessa perspectiva, Pacheco indica que o câncer pode ser uma doença determinada por Deus para punir ou conter as pessoas devido a algo errado que elas tenham feito.

[...] Porque se Ele [Deus] te deu, Ele vai tirar. E se Ele te deu tem algum motivo [...] Se você for voltar atrás na sua vida você vai ver que, talvez, você está passando por aquilo, ou, às vezes, aquilo veio pra te conter também, que muitas das vezes você pode exaltar, você estando muito livre [...] Às vezes eu tô sendo punido por alguma coisa que eu já tenha feito. Eu penso nisso!

Entre a diversidade de tipos de cânceres identificados pelos entrevistados, o câncer da próstata parece assumir um status de mais simples e menos letal, quando comparado aos demais. A crença na menor letalidade desse tipo de câncer parece estar relacionada à possibilidade de retirá-lo, por meio de uma cirurgia. Nesse sentido, Pablo afirma que é possível retirar a próstata e ficar "livre" do câncer: "Se eu tiro a próstata toda fora, aí você tá livre dele". Ou, ainda, Péricles, que afirma: "Ele [câncer de próstata] é mais simples, que é o seguinte: tirou a próstata acabou o seu câncer!"

Observou-se ainda que muitos entrevistados procuraram diferenciar o seu câncer do "câncer dos outros", indicando que, ao contrário dos demais, o seu é menos agressivo e mais tratável: "mas isso é o câncer dos outros! O meu câncer, ele é diferente!" (Pacheco). Conforme destaca Péricles, o seu caso era "mais fácil”, já que seu câncer "estava no início ainda" e "não estava sentindo nada, nada".

Apesar de considerarem o câncer como uma doença grave, temida e letal, também é possível observar na fala dos entrevistados considerações que rompem com esses modos de pensar a doença e passam a compreender o câncer como uma enfermidade comum e normal, conforme destacam Pacheco e Patrício, "igualzinha às outras". Nessa vertente, Patrício afirma que "ninguém deve ter medo do câncer e nem de qualquer outra doença”, uma vez que o adoecimento por câncer "é uma rotina da vida", 
já que "são milhares de pessoas que estão lutando, que vão ter câncer, que têm câncer”.

Pacheco, por sua vez, atribui ao câncer sentidos muito distintos dos demais participantes. Apesar de também considerá-lo como uma doença letal e temida, ele também acha que o câncer "não é a morte", mas sim "um renascimento de uma nova vida, onde você começa a pensar nas coisas boas!". Pacheco explica sua concepção destacando que o câncer chega a ser "até melhor" que outras enfermidades, uma vez que as pessoas, em geral, se preocupam e "cuidam mais dela": "Ela [o câncer], por ser tão temerosa, você cuida mais dela. Outras doenças você acha: Ah, eu tiro de letra! Você começa a tirar ela e não tira totalmente. Aí ela volta pra dentro do corpo e fica lá escondida. Quando ela volta, aquele monstro mais forte e aí fica pior!”

\section{O Tratamento oncológico}

O tratamento oncológico dos entrevistados foi marcado pelo uso constante de medicamentos e sessões de radioterapia, além da indicação de procedimentos cirúrgicos, em especial, de prostatectomia. Analisando o relato dos entrevistados, é possível perceber que os tratamentos ofertados se apresentaram como agressivos e invasivos e se configuraram como produtores de dores e intenso sofrimento.

No que tange à radioterapia, os entrevistados se referem a ela como um procedimento agressivo, que queima o corpo do paciente e atinge, além da parte acometida pelo câncer, outras regiões próximas, produzindo dor e sequelas. Pacheco afirma que as sessões de radioterapia às quais foi submetido eram "tipo um churrasco" e, assim, como Pablo e Péricles, afirma que as sessões "queimavam" todo seu corpo. Segundo Pablo, "quando você faz ela lá [a radioterapia], você não sente nada não". Entretanto, "depois que você faz, você chega em casa e começa a doer". Pablo também relata que, "no período que você acaba de fazer [a radioterapia], a sua boca fica toda ressecada. Você não tem fome pra comer, você não tem sede", contribuindo para a presença de "uma dor muito diferente das outras", semelhante àquela gerada quando "você dá um corte na mão e uma dor diferente da dor de cabeça".

Os entrevistados também destacaram os fortes efeitos percebidos a partir do uso dos medicamentos prescritos durante o tratamento oncológico, que, muitas vezes, trazem alguns efeitos indesejáveis e difíceis de serem administrados. Nesse sentido, Paulo afirma: “aqueles remédios que tomo é muito forte e cada vez vai só me enfraquecendo". Da mesma forma, Pablo afirma que a medicação que toma durante o tratamento "é muito forte e pode atingir seus rins e seu fígado". Desse modo, ao mesmo tempo em que tratavam, as propostas terapêuticas, em especial os medicamentos, as sessões de radioterapia e a prostatectomia, também imprimiam marcas nos corpos dos homens entrevistados.

Alguns dos participantes também relataram que se submeteram a procedimentos invasivos que os deixaram constrangidos, envergonhados e, em alguns casos, revoltados e com a sensação de estarem sendo humilhados, em especial, aqueles que exigem a manipulação do pênis e do ânus. Nesse sentido, depois de se 
submeterem a procedimentos nos quais tiveram um aparelho introduzido no ânus, Paulo, Pacheco e Péricles sentiram, além de dor intensa, um grande constrangimento e um sentimento de revolta.

Entre os procedimentos realizados durante o tratamento oncológico, a prostatectomia foi apontada pelos entrevistados como aquele que trouxe mais prejuízos, sendo considerada, por alguns, como mais agressiva que o próprio câncer. Apesar de muitos entrevistados já terem realizado cirurgias de outras naturezas antes da prostatectomia, eles experienciaram o momento da operação com um medo intenso. Paulo conta que, ao se deitar na mesa de cirurgia, foi tomado pela sensação de que o seu "coração esfriou" e de que parte do seu corpo já havia morrido. Plínio, por sua vez, foi tomado pelo medo do processo cirúrgico e também de que o médico pudesse "fazer maldade" com ele.

Apenas Péricles e Pablo relataram que foram orientados pelos seus médicos quanto aos riscos e danos causados pela prostatectomia. Péricles foi o único que relatou ter assinado o Termo de Consentimento, obrigatório para esse tipo de operação. Nota-se que, apesar da solicitação de consentimento e da prestação de esclarecimentos, por parte do médico, a realização da prostatectomia não lhes foi apresentada como uma escolha, já que a morte era sempre apresentada como certa, caso se recusassem a realizar o procedimento. Nesse sentido, Pablo recorda: "Então os médicos mesmo falou: 'a partir de hoje o senhor vai ter que aceitar! É assim, assim e assim! [...] Mas eu ia fazer o quê? O médico falou: ou você escolhe: ou a morte ou você opera! Aí eu falei: 'eu vou ter que fazer, ué"'.

Ao narrar o evento das cirurgias, os entrevistados chamam a atenção para o fato do quão agressivo esses procedimentos se apresentaram para eles, revelando tratar de um momento de medo, dor e intenso sofrimento. Nesse sentido, Paulo conta que: "foi chegando lá, foi metendo a faca! [...] Aqui eles meteram a mão e tiraram aquele caroço, aquele tumor fora". $\mathrm{Na}$ mesma direção, Péricles afirma que a “cirurgia [da próstata] é violenta! [...] Ela pega aqui, ela vai até no pênis. Isso aqui abre tudo!"

$$
\text { Conforme destaca Pedro, "não é a }
$$
operação em si" que faz com que ela seja percebida dessa maneira, mas sim “as consequências do pós-operatório". Nessa perspectiva, os entrevistados chamam a atenção para os prejuízos gerados pela cirurgia, que, segundo eles, alteram tanto o seu corpo como a sua rotina. Para Pedro, o "pós-operatório é chato mesmo", fazendo com que considere a prostatectomia como a mais chata de todas as cirurgias que realizou. Da mesma forma, Pablo compara a prostatectomia com outras cirurgias e também afirma que "foi a pior de todas". O que aconteceria depois da cirurgia também foi objeto de preocupação para Pierre, que afirma ter sentido muito medo das possíveis consequências que poderiam ser geradas por esse procedimento, como ficar "aleijado, com sequela e com problema".

Apenas Patrício afirmou não ter se abalado com a possibilidade de se submeter à prostatectomia. Ele afirma que "nunca teve medo" da cirurgia, pois já havia realizado outras três cirurgias, e, segundo ele, "não resolve você 
ter medo". Apesar disso, passou a conviver com uma série de mudanças corporais que alteraram sua rotina e hábitos diários, levando-o a constatar que, posteriormente à realização da prostatectomia, "já não é aquele mesmo" de antes.

Deve-se considerar que Pacheco se recusou veementemente a realizar a prostatectomia. Para ele, a cirurgia seria a última alternativa de tratamento, ou, conforme ele mesmo destaca, o "último caso", especialmente por acreditar que "você fez a cirurgia, acabou. Você não tem mais ereção: Se eu tiver que morrer com isso, eu vou morrer! Não adianta! $\mathrm{Eu}$ acho que se eu fizer a cirurgia eu vou ficar pior. Eu vou adoecer mesmo! Aí que eu vou adoecer!"

Depois do adoecimento por câncer e, principalmente, depois da realização da prostatectomia, os participantes afirmam ter experienciado uma série de mudanças corporais que afetaram a maneira como utilizam seus corpos, a forma como se percebem e as suas interações sociais. Entre as principais mudanças percebidas pelos participantes destacam-se o emagrecimento, as mudanças no estado emocional, o isolamento social e, principalmente, as incapacidades funcionais, a incontinência urinária e as disfunções sexuais. Nesse sentido, Paulo relata que, depois do adoecimento e tratamento oncológico, passou a conviver com uma tristeza intensa e a chorar constantemente. Conforme ele mesmo destaca, "Alegria pra mim é choro. Tristeza pra mim é choro [...] tudo ataca a minha cabeça".

Os participantes também passaram a perceber que os seus corpos não mais podiam atender às necessidades do cotidiano da mesma forma como se dava no período anterior ao tratamento oncológico. Nesse sentido, Paulo, Péricles e Pacheco afirmam que já não podem mais fazer esforços físicos, tampouco carregar peso e, além disso, suas pernas "não aguentam" caminhar como antes, restringindo assim a sua rotina. Conforme destacam, "Se eu for de manhã cedo [na igreja], à noite eu não vou porque as pernas não aguentam, fica doendo" (Paulo); "Correr, eu não aguento correr. Andar depressa também me dá cansaço" (Pacheco).

Desse modo, atividades que antes pareceriam fáceis de serem executadas agora não mais podiam ser realizadas ou, se necessário, deveriam passar a contar com a ajuda de terceiros, gerando um sentimento de tristeza e perda da autonomia. Agora, como afirma Pablo, "o corpo não ajuda, não pede pra fazer mais".

As alterações corporais também se configuraram como um grande impeditivo para que os participantes executassem suas atividades, exigindo assim o seu afastamento do trabalho, o que também foi vivenciado com grande tristeza, conforme Paulo destaca.

Então a minha tristeza é que eu [silêncio com choro], a minha tristeza que eu tenho é isso: que eu trabalhava de pedreiro e... fiz... Eu fiz umas... uma, duas, três, quatro... eu fiz cinco casas. Depois dessas cinco casas eu não aguentei mais. [...] Que eu não aguento trabalhar mais, então, [chorando intensamente $[\ldots]$ Porque eu vejo os outros trabalhando, me dá vontade de trabalhar e eu não aguento.

Outra mudança importante, percebida pelos participantes, se refere ao impacto da cirurgia de retirada da próstata no seu 
desempenho sexual, produzindo sentimentos de humilhação, medo e revolta. Segundo o relato de Pablo, desde a constatação do diagnóstico e da necessidade de realização da prostatectomia, sentiu grande "humilhação". As pessoas conversavam com ele e faziam todo "tipo de gozaria: Agora você não vai ó mais [faz um gesto indicando relação sexual], agora você não é homem mais". Em sua opinião, depois dessa cirurgia, em tudo o que faz, "você acha que não é homem mais, que tá sendo humilhado, que os outro mandam em você!"

Pacheco e Pablo destacam que, além da piora no desempenho sexual e dos sintomas de disfunção erétil, também passaram a conviver com a ausência de esperma durante a ejaculação.

Pablo conta que quando consegue manter uma relação sexual "não sai mais nada". Pacheco destaca que, depois da realização das sessões de radioterapia, seu esperma "secou", fazendo com que seu orgasmo não seja mais "aquele orgasmo perfeito", o que o deixa "constrangido e preocupado".

Devido à impossibilidade de alterar o quadro, os participantes se viram às voltas com a necessidade de modificar e adaptar as práticas sexuais. Nesse sentido, Plínio destaca que, agora, ao contrário de antes, durante o ato sexual, ele precisa fazer um esforço para ter e manter a ereção e sua esposa também precisa ajudá-lo.

Paulo, por sua vez, acredita que agora, dadas as mudanças impostas na sua sexualidade, estabelece uma relação de "irmãos", uma vez que não existe mais o ato sexual com penetração, apenas beijos, abraços e carícias. Tal situação deixa Paulo sem saber como agir.
Nós conversa e tudo. Eu abraço ela, aquela coisa toda, mas assim de relação [sexual] acabou mesmo [...] Eu tomo banho junto, eu tomo banho junto com a minha esposa, pra mim é a mesma coisa, é a mesma coisa de eu tá tomando banho sozinho. Ela esfrega a minha cacunda, esfrega os meus pés e eu esfrego a cacunda dela e pra mim é a mesma coisa de nada. Não tá acontecendo nada [...] porque eu fico lembrando: eu não sou homem mais. Não aguento trabalhar, fraqueza nas pernas. Como que eu vou fazer?

Observa-se que, para os entrevistados, torna-se difícil conceber a si mesmos como homens da mesma forma de antes, de maneira que, para muitos, não são mais homens, ou, ainda, se consideram como castrados. Péricles chega a afirmar que o homem que faz a prostatectomia "não vale nada", uma vez que a cirurgia "castra mesmo a pessoa, sabe. Tirou a próstata, acabou". Pacheco, na mesma direção, afirma que, depois da cirurgia, ficou "igual que você castra um porco [...] quando você castra um animal pra poder não ter coisa [sexo]”.

Pacheco, por sua vez, conta que, depois do adoecimento e desde que iniciou o tratamento oncológico, passou a apresentar "um problema na urina, uma incontinência", de maneira que, agora, já não mais consegue "segurar a urina direito". Nesse sentido, urinar nas roupas tornou-se algo que ocorre "muitas vezes", de forma "constante". Desse modo, atividades que antes pareceriam fáceis de serem executadas agora não mais podiam ser realizadas ou, se necessário, deveria passar a contar com a ajuda de terceiros, gerando um sentimento de tristeza e perda da autonomia.

Devido aos sintomas de incontinência urinária e da impossibilidade de controlar a urina, 
os entrevistados se viram diante da necessidade de utilizar fraldas e absorventes descartáveis, o que foi vivenciado por todos como um evento muito desagradável. Para Plínio, o uso das fraldas se referia a algo "terrível": "A fralda é terrível, a fralda é terrível! Porque você, veja bem, com o sol quente dá aquela gastura, né, você na parte de trás, na frente, você entendeu, dá uma gastura terrível".

Segundo Péricles, "o uso de fraldas e absorventes incomoda demais, é ruim pra caramba!" e acaba interferindo em sua rotina diária. Além do desconforto do uso das fraldas e dos absorventes, os entrevistados também chamaram a atenção para o sentimento de vergonha e do medo de que alguém descubra a sua utilização. Péricles relata que, em sua casa, "tem toda a liberdade" para trocar as fraldas, inclusive "na vista de seus filhos". Entretanto, levar e trocar as fraldas na casa de outras pessoas o deixa envergonhado e incomodado, fazendo com que evite sair: "Não quero ir só por causa disso, porque incomoda bastante!” De forma semelhante, Pedro afirma que, agora, está "desesperado" com a utilização das fraldas, já que elas estão interferindo em sua rotina.

\section{Discussão}

Conforme destacado anteriormente, a experiência tem duas dimensões intimamente relacionadas: a do vivido/experimentado e a do conhecimento/cognitivo (Jodelet, 2005; Jodelet, 2006). No que tange à dimensão da experiência vivida, no presente estudo, embora cada participante tenha recebido a notícia do diagnóstico de câncer da próstata e tenha experienciado o processo de adoecimento e tratamento oncológico de forma singular, a análise das narrativas também indica situações em que essas experiências se aproximam, revelando marcas do contexto social no qual o grupo de homens encontra-se inserido. Em geral, os entrevistados afirmaram ter recebido $\mathrm{O}$ diagnóstico de câncer com certa surpresa e relataram que, ao receber a notícia, se mantiveram calmos e tranquilos.

Entretanto, à medida que o tratamento oncológico se iniciava, os homens começavam a se deparar com uma nova realidade até então pouco familiar, geradora de sentimentos de medo, ansiedade e receios quanto à possibilidade do sofrimento e morte. Esses dados também vêm sendo constatados em outros estudos que, como já mencionado, apontam para a experiência de adoecimento por câncer como geradora de sentimentos de tristeza, sofrimento e medo (Gomes et al., 2008; Mesquita et al., 2011; Burlle et al., 2013; Modena et al., 2014; Martins \& Modena, 2016; ; Chambers et al., 2017).

No que se refere à dimensão do conhecimento/cognitivo, é possível observar que os participantes, ao mesmo tempo em que experienciam o adoecimento e o tratamento oncológico, também produzem sentidos para sua experiência. Sendo assim, para grande parte dos entrevistados, o câncer foi percebido como uma doença grave, complexa, agressiva e fortemente associada à morte. Diversos estudos apontam para as concepções negativas do câncer que ainda se encontram (re)produzidas e difundidas na sociedade brasileira (Modena et al., 2014; Novak \& Sabino, 2015; Martins \& Modena, 2016a). Como pôde ser observado na 
fala dos homens entrevistados, apesar dos avanços nos tratamentos oncológicos e do aumento das possibilidades de cura e reabilitação dos pacientes acometidos por essa enfermidade, o câncer ainda é concebido como uma doença grave e mortal, sendo fortemente associado à morte, ao castigo, à dor e ao sofrimento (Mesquita et al., 2011; Martins et al., 2012; Martins \& Modena, 2016; Chambers et al., 2017).

Vale ressaltar que as limitações físicas e a nova rotina impostas pelo adoecimento e tratamentos mostram-se bastante diferentes dos modos de vida dos homens anteriores à enfermidade (Gomes et al., 2008; Burille et al., 2013; Modena et al., 2014; Chambers et al., 2017). Frequentemente necessárias, a internação hospitalar e a visita constante a profissionais e serviços de saúde revelam ao homem um mundo pouco familiar, marcado por perda da autonomia e controle de si, gerando sentimentos de ansiedade e inadaptação (Gannon et al., 2010; Burille et al., 2013; Modena et al., 2014; Martins \& Modena, 2016a).

Portanto, como apontam as falas dos entrevistados, e em consonância com outros estudos, as implicações do adoecimento e tratamento oncológico não se restringem à dimensão biológica, de modo que as alterações corporais também produzem implicações psicossociais (Gomes et al., 2008; Gannon et al., 2010; Krumwiede \& Krumwiede, 2012; Martins et al., 2012; Modena et al., 2014).

No que tange às propostas terapêuticas, em especial aos medicamentos, às sessões de radioterapia e à prostatectomia, ao mesmo tempo em que tratavam, elas também imprimiam marcas nos corpos dos homens entrevistados. Cotidianamente, os sujeitos se viam diante da necessidade de submeter os seus corpos a procedimentos e ações que pouco conheciam, mas que lhes eram impostas como necessárias. Assim, os participantes passaram a experienciar um cotidiano marcado pela dor intensa e pelo desconforto físico e psicológico, além das sequelas que o tratamento produzia.

Entre as modificações corporais produzidas pelo adoecimento e tratamento oncológico, a incontinência urinária e a impotência sexual foram apontadas como as mais significativas e impactantes para o grupo de homens entrevistados. Ao se depararem com a incontinência urinária, os participantes passaram a vivenciar sentimento de perda de autonomia e controle sobre seus corpos, exigindo, assim, o uso de absorventes e fraldas descartáveis, que, além de desconforto físico, também produziam um mal estar psicológico. De forma semelhante, a perda da capacidade de ter e/ou manter uma ereção produziu nesses sujeitos o sentimento de diminuição de sua masculinidade, levando-os a considerar que não são mais homens como antes.

As mudanças anatômicas e funcionais em seus corpos também exigiam a reorganização de suas rotinas diárias. Nesse sentido, muitos desses homens se viram às voltas com a necessidade de afastamento das atividades de trabalho e emprego, gerando grande tristeza. Em grande parte dos relatos, é possível observar que o adoecimento, a rotina e as limitações impostas pelos tratamentos também contribuíam para o isolamento social desses sujeitos, incidindo, assim, sobre suas 
interações e vínculos sociais.

Resultados semelhantes vêm sendo apontados na literatura. Modena et al. (2014) analisaram a experiência de homens acometidos por diferentes tipos de câncer e também identificaram que a nova condição física imposta pelo adoecimento, a exposição a procedimentos agressivos e invasivos e a rotina assistencial contribuíam para que os homens adoecidos vivenciassem sentimentos de tristeza, medo e angústia. $\mathrm{Na}$ mesma vertente, em um estudo conduzido com homens do sul do país, Burille et al. (2013) chamam a atenção para o impacto das mudanças corporais produzidas durante $\mathrm{O}$ adoecimento e tratamento oncológico na rotina diária dos homens. As autoras destacam que, para além das mudanças que acometem pacientes dos ambos os sexos, os homens vivenciam uma pressão para continuar atestando sua virilidade, quase sempre, questionada em função da perda da força física, incontinência urinária e disfunções sexuais.

Outros estudos apontam que as mudanças corporais impostas pelo adoecimento por câncer exigem dos homens uma reformulação da sua autoimagem e afetam as atitudes sobre si mesmos, contribuindo, assim, para a redefinição de papéis sociais (Gannon et al., 2010, Burille et al., 2013, Modena et al., 2016a). Nesse sentido, depois do descobrimento da doença e durante todo o tratamento oncológico, os homens são convocados a reconstruírem a maneira de perceber seus corpos, refletindo na ressignificação de sua própria identidade (Campbell et al., 2014; Martins \& Modena, 2016a).

Considerando-se que o exercício de poder é uma das prerrogativas masculinas mais evidentes (Connel \& Messerschmidt, 2013), o seu exercício se torna comprometido ao tentar exercê-lo utilizando fraldas e absorventes descartáveis. O mesmo parece se repetir em outras situações que passaram a constituir o cotidiano dos homens entrevistados. Ao contrário do período anterior ao adoecimento, esses sujeitos passaram a vivenciar uma perda e/ou subtração do seu poder tanto em relação aos seus próprios corpos como também em suas relações com outros homens e mulheres. Em algumas situações, especialmente naquelas em que se viam diante da necessidade de entrega dos seus corpos a exames como os de toque retal, esses homens vivenciam sentimentos de sujeição e ausência absoluta do poder, gerando sentimentos de revolta, raiva e tristeza.

$$
\text { Considerando-se os padrões }
$$
hegemônicos de corpos masculinos difundidos em nossa sociedade, as mudanças corporais produzidas pelo adoecimento e tratamento oncológico parecem contribuir para o sentimento de que seus corpos falharam na sustentação dos ideais e padrões estabelecidos pelo modelo de masculinidade, provocando-os a ressignificar seus modos de pensar, sentir e agir em relação aos seus corpos e à sua própria masculinidade (Gannon et al., 2010; Krumwiede \& Krumwiede, 2012; Novak \& Sabino, 2015).

Tais achados somam-se aos resultados de outros estudos semelhantes. A partir de uma revisão sistemática de estudos sobre os impactos das mudanças corporais, em especial a disfunção erétil, entre homens que concluíram o tratamento por câncer da próstata, Chambers et al. (2017) constataram uma forte associação 
entre a disfunção erétil, pós-prostatectomia, com sentimentos de redução da masculinidade. Os autores também observaram que, para esses sujeitos, as disfunções sexuais produzem o sentimento de vergonha, constrangimento e autovalor reduzido, gerando prejuízos para a saúde mental e qualidade de vida (Chambers et al., 2017).

Analisando as transformações corporais de homens residentes no Reino Unido, Kelly (2009) ressalta que, depois do adoecimento por câncer de próstata, os homens se veem diante da necessidade de conviver com um novo corpo, que lhes parece estranho e não familiar. $\mathrm{O}$ autor constata que, depois do processo de adoecimento e tratamento oncológico, os homens passam a conviver com o sentimento de que seus corpos falharam para sustentar os padrões do modelo de masculinidade hegemônica, impactando assim o self e a identidade desses sujeitos.

Em um estudo semelhante, realizado nos Estados Unidos, com um grupo de homens que também foram diagnosticados com câncer da próstata, Krumwiede e Krumwiede (2012) identificaram que, depois do tratamento oncológico, os sujeitos passam a conviver com o sentimento de perda do controle dos seus corpos, manifestando a sensação de estarem desconectados destes. As disfunções sexuais e urinárias, vivenciadas pelos participantes do referido estudo, produziram o sentimento de humilhação e vergonha e contribuíram para o aumento do nível de estresse.

Gannon et al. (2010) investigaram o impacto das mudanças corporais entre homens que realizaram a prostatectomia radical. Os autores constataram que a realização dessa cirurgia produz alterações corporais difíceis de serem suportadas pelos homens, produzindo alterações também nos seus sentimentos de masculinidade. As disfunções sexuais que emergiram depois da prostatectomia exigiram que esses sujeitos reconstruíssem os sentidos atribuídos ao ser homem e buscassem novas formas de exercitar sua masculinidade.

No contexto brasileiro, Mesquita et al. (2011) identificaram, entre um grupo de homens com diferentes tipos de câncer, o sentimento de não ser $\mathrm{o}$ mesmo de antes. As mudanças corporais e as perdas a elas associadas produziram nesses sujeitos o sentimento de não serem tão homens como antes do adoecimento, levando-os a refletir sobre suas vidas e a modificar suas crenças acerca de sua própria masculinidade. $\mathrm{Na}$ mesma direção, Burille et al. (2013) e Modena et al. (2014) também identificaram um impacto significativo das mudanças corporais advindas depois do adoecimento por câncer e tratamento oncológico na identidade masculina de homens brasileiros.

\section{Considerações finais}

No presente estudo, foi possível realizar uma aproximação das experiências de adoecimento por câncer da próstata, um tema ainda pouco explorado na literatura científica nacional. Apesar de se configurar como um processo difícil de ser suportado, o adoecimento por câncer e o tratamento oncológico exigiram que os homens reelaborassem suas concepções acerca de seus corpos e, ao mesmo tempo, 
parece ter favorecido um espaço para construção de novas formas de se pensar e viver a própria masculinidade.

Desse modo, percebe-se que, juntamente com a dor do adoecimento, os homens experienciam outro sofrimento, relacionado às tentativas de manutenção da sua virilidade para si mesmos e para os grupos aos quais pertencem. Entretanto, as mudanças corporais, em especial aquelas relacionadas às disfunções sexuais, denunciam que eles já não podem mais exercitar a sua masculinidade como no período anterior ao adoecimento. Desse modo, apesar da dor e sofrimento, nota-se que o adoecimento e o tratamento do câncer da próstata também se despontam como uma oportunidade para que os homens possam repensar e reconstruir os sentidos e os modos de exercitar suas masculinidades.

Nesse sentido, diante de uma nova corporeidade que, devido aos impactos do adoecimento e do tratamento oncológico, distanciava-se dos ideais impostos pelo modelo de masculinidade hegemônica, em especial no que tange à força física e ao desempenho sexual, os homens foram pressionados a ressignificar os seus modos de conceber e exercitar suas masculinidades. A análise das narrativas desses sujeitos revela que esse é um processo doloroso e de difícil elaboração, contribuindo para o sentimento de não serem mais homens, como no período que antecede ao adoecimento. Portanto, ressalta-se a necessidade de os profissionais que ocupam as equipes interdisciplinares em Oncologia considerarem as implicações psicossociais do adoecimento e tratamento, em especial no que se refere ao processo de construção social das masculinidades.

Por fim, vale ressaltar que os dados aqui apresentados e discutidos dizem respeito às experiências de um grupo de homens idosos e pobres. Outros estudos poderão ser realizados, considerando outras pertenças sociais e analisando como os aspectos geracionais, territoriais e de classe social também podem interferir e delinear outras experiências de adoecimento por câncer da próstata.

Acreditamos que o estudo das experiências de adoecimento masculino por câncer seja um importante caminho para a promoção e a consolidação de práticas em saúde que se comprometam com a superação dos modelos exclusivamente biomédicos e que busquem a construção de novos modos de pensar, sentir e agir em saúde, pautados em uma perspectiva de saúde integral e indissociada dos contextos histórico, sociocultural e político no qual os sujeitos estão inseridos.

\section{Referências}

Almeida, A., \& Santos, M. (2011). Representações sociais masculinas de doença e saúde. In Z. Trindade, M. Menandro \& C. Nascimento (Orgs.). Masculinidades e práticas de saúde. Vitória: GM Editora.

Amorin, V., Barros, M., César, C., Goldbaum, M., Carandina, L., \& Alves, M. (2011). Fatores associados à realização dos exames de rastreamento para o câncer de próstata: um estudo de base populacional. Cadernos de Saúde Pública, 27(2), 347-356.

Belinelo, R., Almeida, S., Oliveira, P., Onofre, P., Viegas, S., \& Rodrigues, A. (2014). Exames de rastreamento para o câncer de próstata: vivência de homens. Escola Anna 
Nery, 18(4), 697-704.

Burille, A., Schwartz, E., \& Zillmer, J. G. V. (2013). Mudanças no cotidiano de homens com câncer: apresentando uma das interfaces do adoecer. Revista Pesquisa: Cuidado Fundamental, 5(2), 3539-3548.

Campbell, L., Keefe, F., \& McKee, D. (2014). Masculinity beliefs predict psychosocial functioning in african american prostate cancer survivors. American Journal of Men's Health, 6(5), 400-408.

Chambers, S., Chung, E., Wittert, G., \& Hyde, M. (2017). Erectile dysfunction, masculinity, and psychosocial outcomes: a review of the experiences of men after prostate cancer treatment. Translational Andrology and Urology, 6(1), 60-68.

Connell, R. \& Messerschmidt, J. (2013). Masculinidade hegemônica: repensando o conceito. Revista de Estudos Feministas, 21(1), 241-282.

Flick, U. (2009). Introdução à pesquisa qualitativa (3a ed.). Porto Alegre: Artmed.

Gannon, K., Guerro-Blanco, M., Patel, A., \& Abel, P. (2010). Re-construction masculinity following radical prostatectomy for prostate cancer. The Aging Male, 13(4), 258-264.

Giorgi, A. (2008). Sobre o método fenomenológico utilizado como modo de pesquisa qualitativa nas ciências humanas: teoria, prática e avaliação. In J. Poupart (Org.). A pesquisa qualitativa: enfoques epistemológicos e metodológicos. Petrópolis: Vozes.

Gomes, R., Nascimento, E., Rebello, L., \& Araújo, F. (2008). As arranhaduras da masculinidade: uma discussão sobre o toque retal como medida de prevenção do câncer prostático. Ciência \& Saúde Coletiva, 13(6), 1975-1984.

Instituto Nacional do Câncer [Inca]. (2016). Estimativa 2020: incidência de câncer no Brasil. Recuperado em 22 junho, 2020, de https://www.inca.gov.br/sites/ufu.sti.inc a.local/files/media/document/estimativa -2020-incidencia-de-cancer-no-brasil.pdf.
Jodelet, D. (2005). Experiência e representações sociais. In M. S. S. Menin \& A. A. Shimizu. (Orgs.). Experiência e representação social: questões teóricas e metodológicas. São Paulo: Casa do Psicólogo.

Jodelet, D. (2006). Presença da cultura no campo da saúde. In A. Almeida, M. F. S. Santos, G. R. S. Diniz \& Z. A. Trindade. Violência, exclusão social e desenvolvimento bumano: estudos em representações sociais. Brasília: Editora UnB.

Kelly, D. (2009). Changed men: the embodied impact of prostate cancer. Qualitative Health Research, 19(2), 151-163.

King, A., Evans, M., Moore, T., Paterson, C., Sharp, D., Persad, R., \& Huntley, A. (2015). Prostate cancer and supportive care: a systematic review and qualitative synthesis of men's experiences and unmet needs. European Journal of Cancer Care, 24, 618-634.

Krumwiede, K. A., \& Krumwiede, N. (2012). The lived experience of men diagnosed with prostate cancer. Oncology Nursing Forum, 39(5), 443-540.

Martins, A. M., Gazzinelli, A. P., Almeida, S. S. L., \& Modena, C. M. (2012). Concepções de psicólogos sobre o adoecimento de homens com câncer. Psicologia: Teoria e Prática, 14(2), 74-87.

Martins, A., Gazzinelli, A., Almeida, S., \& Modena, C. (2013). A assistência psicológica aos homens com câncer: reflexões na perspectiva de gênero. Revista da SBPH, 16, 49-69.

Martins, A., \& Modena, C. (2016a). Câncer e masculinidades: o sujeito e a atenção à saúde. Curitiba: Editora Juruá.

Martins, A., \& Modena, C. (2016b). Estereótipos de gênero na assistência ao homem com câncer: desafios para a integralidade. Trabalho, Educação e Saúde, 14(2), 399-420.

Mesquita, M. G. R., Moreira, M. C., \& Maliski, S. L. (2011). "But I'm (became) different". Cancer Nursing, 34(2), 150-157.

Modena, C. M., Martins, A. M., Gazzinelli, A. P., 
Almeida, S. S. L., \& Schall, V. T. (2014). Câncer e masculinidades: sentidos atribuídos ao adoecimento e ao tratamento oncológico. Temas em Psicologia, 22(1), 67-78.

Moreira, M. C. N., Gomes, R., Ribeiro, C. R. (2016). E agora o homem vem?! Estratégias de atenção à saúde dos homens. Cadernos de Saúde Pública, 31(4), $1-10$.

Moura, E., Gomes, R., \& Pereira, G. (2017). Percepções sobre a saúde dos homens numa perspectiva relacional de gênero, Brasil, 2014. Ciência \& Saúde Coletiva, 22(1), 291-300.

Nascimento, A., Trindade, Z., \& GianordoliNascimento, I. (2011). Homens brasileiros jovens e representações sociais de saúde e doença. Psico-USF, 16, 203-213.

Novak, J., \& Sabino, A. (2015). Efeitos psicossociais da prostatectomia radical em pacientes com câncer de próstata. Revista Arquivos de Ciências da Saúde, 22(3), 15-20.

Paiva, E., Motta, M., \& Griep, R. (2011). Barreiras em relação aos exames de rastreamento do câncer de próstata. Revista Latino Americana de Enfermagem, 19(1), 1-8.

Schwarz, E., Gomes, R., Couto, M. T., Moura, E. C., Carvalho, S. A., \& Silva, S. F. C. (2012). Política de Saúde do Homem. Revista de Saúde Pública, 46(supl. 1), 108-16.
Smith, J. A., \& Eatough, V. Análise Fenomenológica Interpretativa. In G. M. Breakwell, C. Fife-Schaw, S. Hammond \& J. A. Smith (Orgs.). (2010). Métodos de Pesquisa em Psicologia (pp. 321-339). Porto Alegre: Artmed.

Trindade, Z. A., Menandro, M. C. S., \& Gianordoli-Nascimento, I. F. (2007). Organização e interpretação de entrevistas: uma proposta de procedimento a partir da perspectiva fenomenológica. In M. M. P. Rodrigues \& P. R. M. Menandro (Orgs.). Lógicas metodológicas: trajetos de pesquisa em psicologia (pp. 71-92). Vitória/ES: Programa de Pós-graduação em Psicologia/Editora GM. 